\title{
Correction to: Requirement or exclusion of inverted repeat sequences with cruciform-forming potential in Escherichia coli revealed by genome-wide analyses
}

\author{
Osamu Miura $^{1,2} \cdot$ Toshihiro Ogake $^{2} \cdot$ Takashi Ohyama $^{1,2}$
}

Published online: 22 August 2018

(c) The Author(s) 2018

\section{Correction to: Current Genetics (2018) 64:945-958 https://doi.org/10.1007/s00294-018-0815-y}

The article 'Requirement or exclusion of inverted repeat sequences with cruciform-forming potential in Escherichia coli revealed by genome-wide analyses' written by Osamu Miura, Toshihiro Ogake, Takashi Ohyama was originally published online on SpringerLink with open access.

The copyright was incorrect in the article HTML version and it should read as 'The Author(s) 2018'.
The original article HTML version has been corrected.

Open Access This article is distributed under the terms of the Creative Commons Attribution 4.0 International License (http://creativeco mmons.org/licenses/by/4.0/), which permits unrestricted use, distribution, and reproduction in any medium, provided you give appropriate credit to the original author(s) and the source, provide a link to the Creative Commons license, and indicate if changes were made.
Takashi Ohyama

ohyama@waseda.jp

1 Department of Biology, Faculty of Education and Integrated Arts and Sciences, Waseda University, 2-2 Wakamatsu-cho, Shinjuku-ku, Tokyo 162-8480, Japan

2 Major in Integrative Bioscience and Biomedical Engineering, Graduate School of Science and Engineering, Waseda University, 2-2 Wakamatsu-cho, Shinjuku-ku, Tokyo 162-8480, Japan 